\title{
Experimental investigation on foamed concrete produced using a planetary ball mill
}

\author{
Eva Namsone ${ }^{1}$, Genadijs Sahmenko², Elvija Namsone ${ }^{3}$, Endija Namsone ${ }^{4}$, \\ Aleksandrs Korjakins ${ }^{5}$, Diana Bajare ${ }^{6}$ \\ Institute of Materials and Structures, Faculty of Civil Engineering, Riga Technical University, Riga, Latvia \\ E-mail: ${ }^{5}$ aleksandrs.korjakins@rtu.lv (corresponding author)
}

\begin{abstract}
The experimental study is devoted to investigation on foamed concrete produced applying innovative intensive mixing technology by using a planetary ball mill. Modern type of foamed concrete represents cementitious composite material group which may be competitive with traditionally used autoclaved aerated concrete. Innovative mixing method makes possible stabilizing of foamed concrete mixture and improving the microstructure of material. The aim of this study is to investigate physical and mechanical properties of non-autoclaved concrete such as density and compressive strength, and capillary water absorption depending on intensive mixing time. In this research microstructure, such as pore size diameters, depending on mixing time is also analysed.
\end{abstract}

Keywords: foamed concrete, mixing technology, activation.

\section{Introduction}

Nowadays, civil engineering construction is one of the most important industries not only in manufacturing processes, but also in energy consumption. At the moment the sector of building has reached almost half of total energy consumption - in general they are 40 percent. (Namsone, Sahmenko, Namsone, \& Korjakins, 2017a, 2017b).

Since the environment is contaminated by many different factors, including production, industrial activities and construction, therefore more attention is also paid to environmental pollution and caused $\mathrm{CO}_{2}$ emissions. There are published documents about reduction of pollution and $\mathrm{CO}_{2}$ emissions by the European Union - the Paris Agreement, also the directive EU 2010/31/EU (United Nations, 2015). The aim is to limit emissions about $20 \%$ up to 2020 and $40 \%$ up to 2030 (European Union, 2010; Namsone, Korjakins, Sahmenko, \& Sinka, 2017).

Engineering scientists also are trying to optimize the processes of material production. More and more modern materials are being developed and produced (Kharitov, Korobkova, \& Smirnova, 2015; Smirnova, 2018), so the amount of needed resources would be reduced. So one of the main purposes is to obtain evironmentally friendly building materials that would be also durable, for example, foamed concrete (FC) (Namsone et al., 2017a).

One of the main modern building materials is lightweight concrete. They have moderate strenght and good insulation properties. There are divided two types of cellural concrete that are used in nowadays - FC and AAC (aerated autoclaved concrete) (Zhang, Jiang, Li, \& Wu, 2018). AAC is obtained by chemical aeration with special gas mixture. As the most popular material is autoclaved gas silicate concrete and they are described by high porosity and water absorption (Namsone, Sahmenko, \& Namsone, 2018; Namsone, Sahmenko, \& Korjakins, 2017c).

The other kind is FC which is also know as lightweight concrete with density from 350 to $1600 \mathrm{~kg} / \mathrm{m}^{3}$. FC is universal materal and main qualities are simply molding and production technology, good mechanical parameters (Tanveer, K. Jagdeesh, \& F. Ahmed, 2017; Tan, Chen, Hao, \& Wang, 2014). The lightweight, water absorption and insulation are advantages properties of this material (C. Sun, Zhu, Guo, Zhang, \& G. Sun, 2018). So it is one of the more widly used building materials not only for prefabricated but also monolithic constructive elements (Namsone et al., 2017c; Namsone et al., 2018).

But comparing to aerated autoclaved concrete, the use of FC is limited according to lower compressive strenght values and bad shrinkage behaviour. There can be used different pore-forming additives and fibres with high strength to improve necessary mechanical and physical properties of material (Namsone et al., 2017c; Namsone et al., 2018).

The aim of this study is to explore innovative mixing technology of producing FC by using a planetary ball mill. This method is new and unkown in practical use. The main benefits are simultaneous mixing, foaming and ac- 
tivation of ingredients. All agglomerates of cement and especially of silica fume are divided. The specific surface of cement increases.

\section{Materials and methods}

\section{Used materials}

The compositions of FC were elaborated experimentally. For preparation of FC, the following components were used.

As the main binding agent, the normal type Portland cement CEM $42.5 \mathrm{~N}$ was used. The specific surface of the used Portland cement $-3500-3900 \mathrm{~cm}^{2} / \mathrm{g}$, the values of compressive strength is no less than $10 \mathrm{MPa}$ after 2 dayss and no less than 42.5 MPa after 28 dayss (according to the producer "CEMEX", Ltd. Information).

As filling component in this experimental study natural, washed sand with fraction size $0.4-1.2 \mathrm{~mm}$ was used. The sand is not only filler in the FC composition, but also helps to promote the foaming process during the mixing process.

During the mixing a synthetic foaming agent (PB-Lux) and superplasticizer Stachement was added (according to the mixed foaming method).

The following pozzolanic additives were added: microsilica or silica fume (MS), metakaolin (MK) and fly ash (FA). MS has fine, spherical shape particles; about 100 times smaller than particles of Portland cement (average diameter $0.10 \mu \mathrm{m}$ ) and it works as the supplementary cementing material (Hwang \& Tran, 2015; Just \& Middendorf, 2009). MK is the technogenic waste material, obtained from the manufacturing process of expanded glass granules in a form of powder. MK has several advantages: it improves the workability and durability properties of concrete; by adding the pozzolanic admixtures, the risk of the potential alkali-silica reactions that may occur between the Portland cement and glass aggregate, is decreased. FA are dusty particles that are collected in dust extraction systems of thermal power plants; formed as by-product of the combustion process of coal, lignite and other solid fuels (Ding \& $\mathrm{Li}$, 2002; Zhang, Provis, Reid, \& Wang, 2015).

Porous aggregate (cenospheres) was used in the production of FC mixes. Cenospheres is one of the by-products of coal combustion process as well. These are small, hollow spheres (see Figure 1) with an average diameter of 30 $350 \mu \mathrm{m}$. The low density and high mechanical strength values (20-100 MPa), thermal insulation and acoustic properties, inertness against acids and alkalis promotes cenospheres application in different sectors (Krämer, Kowald, \& Trettin, 2015; Fomenko \& Anshits, 2015).

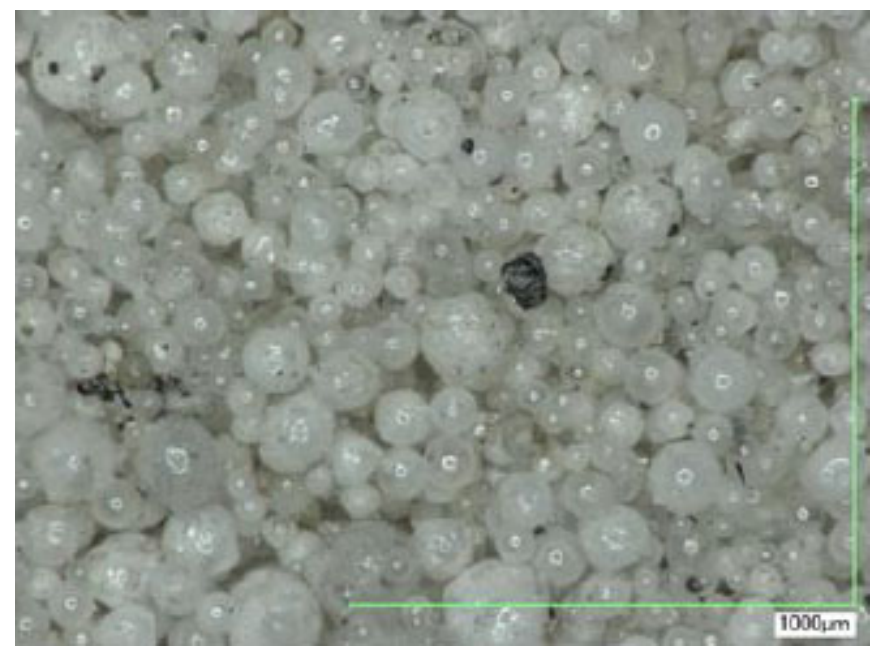

Figure 1. Porous aggregate used in the mixes of FC (microscope image of CS)

To the FC mixes the polycarboxylate based superplastifying chemical admixture, produced by "Stachema", was added.

\section{Preparation of FC samples}

The samples of FC were prepared using mixed foaming technology and planetary ball mill PM 400 (produced by "Retsch", see Figure 2) with the functions of mixer, grind and homogenization. PM 400 is a robust floor model and has 4 grinding stations (Retsch $\mathrm{GmbH}, 2017$ ). 

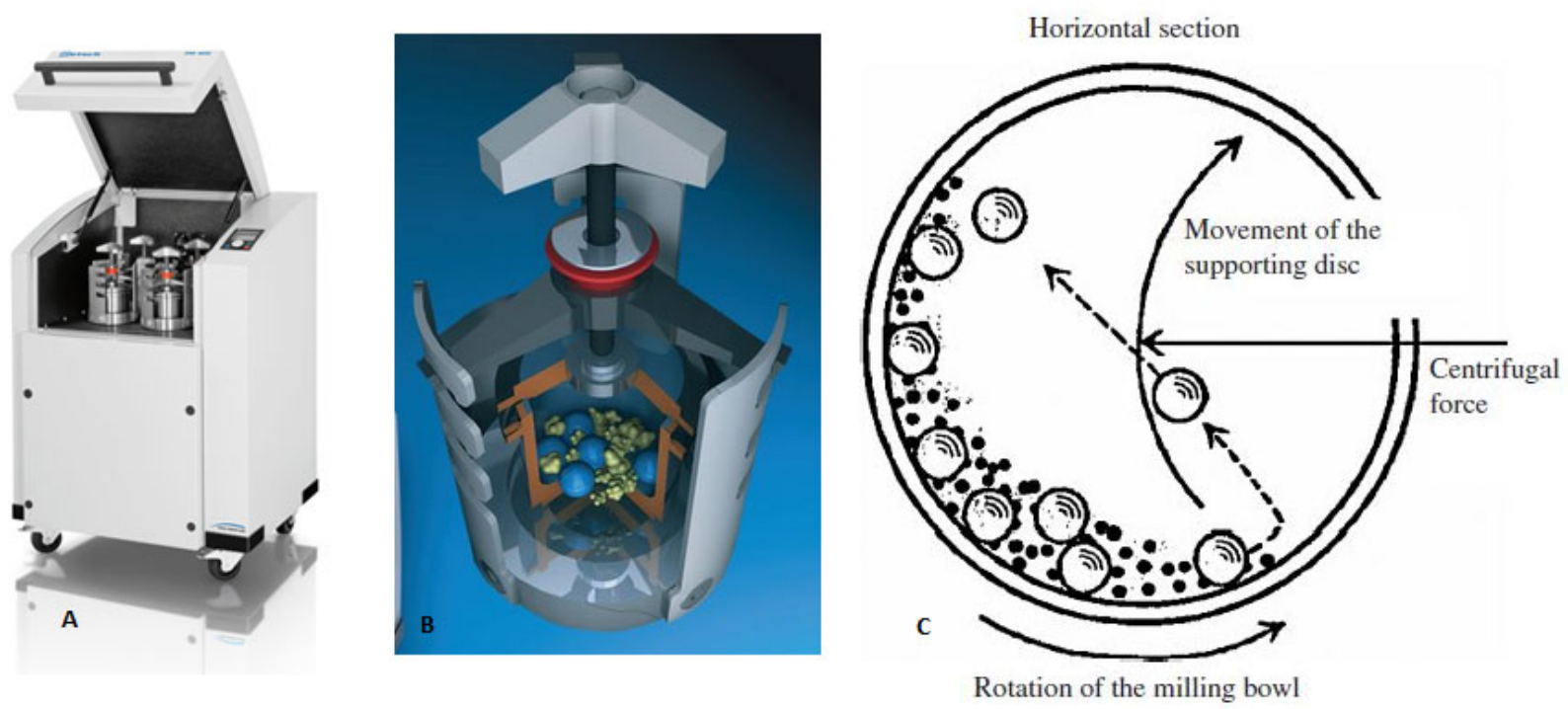

Figure 2. Planetary ball mill "Retsch" PM 400 used in the process of mixing (A), grinding jar (B), schematic view of working principle of the ball and powder mixture (C) (G. Sun et al., 2018; Hwang \& Tran, 2015)

Powder mixture is placed in the ball mill in the grinding jar and during the process of intensive mixing is subjected to high energy collision from the balls. The rotation directions of the milling bowl and the turn disc are opposite. The grinding jars are located eccentrically on the sun wheel (Retsch GmbH, 2017; Cao, n.d.).

In this experimental study different mixing time was set $-1,2,3$ and 4 minutes and the number of balls was dectreased upto 8 in one bowl. Mixtures A and C were produced without pozzolanic additives, water/cement ratio was different (see data in Table 1). Experimental mixes FLY, FLY 3 and CS were produced using pozzolanic additives. In the mix CS sand was replaced by cenospheres.

Table 1. Mix designations (weight proportions of the cement amount)

\begin{tabular}{|l|c|c|c|c|c|}
\hline \multirow{2}{*}{ Ingredients } & \multicolumn{5}{|c|}{ Designations of mixes } \\
\cline { 2 - 6 } & $\mathrm{A}$ & FLY 3 & FLY & $\mathrm{C}$ & CS \\
\hline Cement & 1.00 & 1.00 & 1.00 & 1.00 & 1.00 \\
\hline Sand & 1.43 & 0.91 & 0.63 & 1.25 & 0 \\
\hline SF & 0.06 & 0.08 & 0.05 & 0.06 & 0.10 \\
\hline MK & 0.10 & 0.11 & 0.08 & 0.10 & 0 \\
\hline Fly ash & 0 & 0.43 & 0.11 & 0 & 0 \\
\hline Cenospheres & 0 & 0 & 0 & 0 & 0.73 \\
\hline Stachema & 0.01 & 0.01 & 0.01 & 0.01 & 0.02 \\
\hline Water & 0.46 & 0.70 & 0.49 & 0.69 & 0.50 \\
\hline
\end{tabular}

\section{Testing methods}

According to standart LVS EN 12390-3 (Latvijas standarts, 2002), the test of compressive strength was performed. The samples with standard dimensions $(100 \times 100 \times 100 \mathrm{~mm})$ were tested at the age of 7 and 28 dayss using universal testing machine "Zwick Z100" and applying the force with speed $10 \mathrm{~mm} / \mathrm{min}$. The specimens were stored at the temperature $15-20{ }^{\circ} \mathrm{C}$ and relative humidity $>90 \%$. The relation between the values of compression strength, density and mixing time was determined.

In this experimental study the test of capillary water absorption, using the methodology of standart LVS EN 772-11 (Latvijas standarts, 2011), was performed. The samples were immersed in water in a depth of $5 \mathrm{~mm}$ and masses of the specimens were controlled after 10,15, 30 minutes and 1, 48 hours (since the start of the test). The coefficient of the capillary water absorption was calculated:

$$
C=\left(m_{s}-m_{d}\right) / A_{S},
$$

where: $m_{s}-$ the mass of the sample after soaking, g; $m_{d}-$ the mass of the sample after drying, g; $A_{S}-$ the cross area of the sample surface immersed in water, $\mathrm{dm}^{2}$. 
Microstructure of prepared specimens was researched by the optical microscope VHX-2000 "Keyence Corporation". The images obtained were investigated by using computer programme "VHX-2000 Analyzer"; the average pore size of the FC matrix and correlation between density and pore size was determined.

Specific compressive strength was calculated:

$$
K=\frac{R}{\rho},
$$

where: $\rho$-density, $\mathrm{g} / \mathrm{cm}^{3} ; R-$ compressive strength, Mpa.

\section{Results and discussion}

Density

The results of density of the age of 28 days obtained from all produced FC mixes are summarized in the graph (see Figure 3).

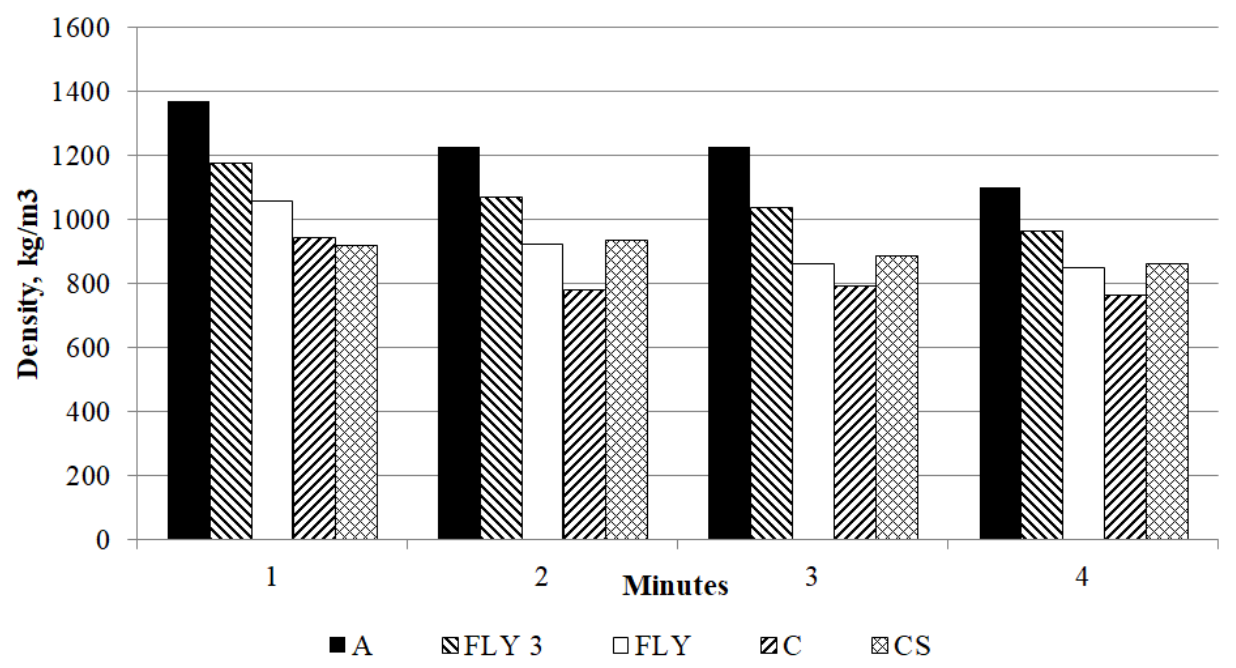

Figure 3. Density, $\mathrm{kg} / \mathrm{m}^{3}$ (28 days) depending on mixing time (minutes)

The data from this experiment permits to conclude that density has decreasing tendency by longer activated mixing with some exceptions. Higher values of density showed mix without pozzolanic additives (mix A) and with 0.49 water/cement ratio. It also can be concluded that by increasing water/cement ratio up to 0.69 , the density decreases and are stabile from two to four activated mixing minutes (see results of mix $\mathrm{C}$ ). Results show that by using fly ash, values of density increase (see results of mix FLY and FLY 3) comparing to composition with cenospheres. It also can be concluded that higher value of density $\left(1070 \mathrm{~kg} / \mathrm{m}^{3}\right)$ is obtained for FC with $30 \%$ of fly ash.

\section{Compressive strength}

The results of compressive strength of FC in the age of 7 days obtained for all produced FC mixes are summarized in the graph (see Figure 4).

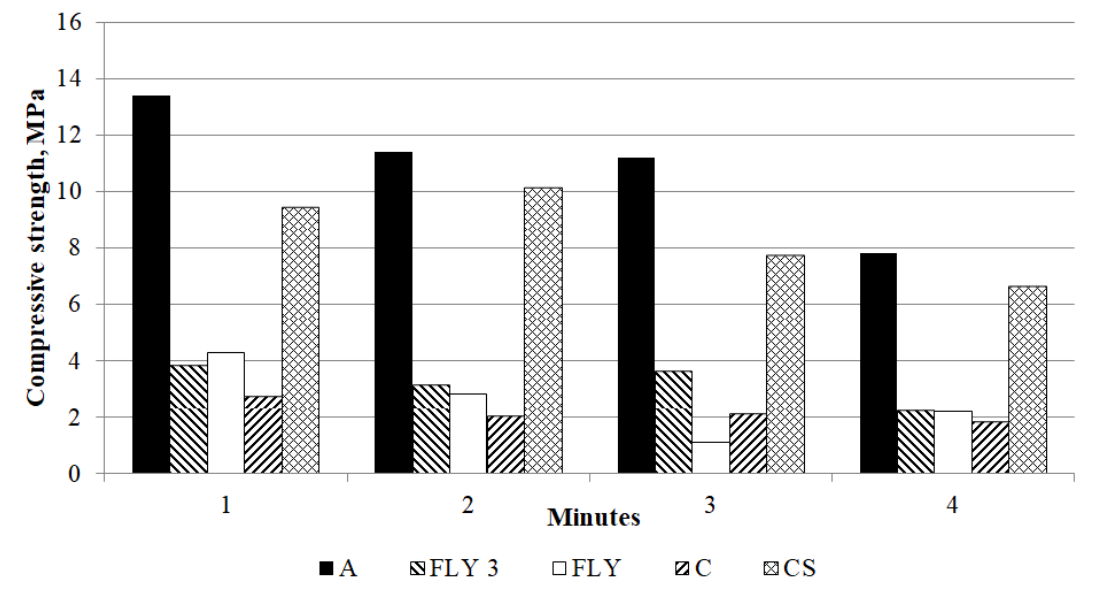

Figure 4. Compressive strength, MPa (7 days) depending on mixing time (minutes) 
The data from this experiment permits to conclude that compressive strength have decreasing tendency by longer activated mixing with some exceptions. Higher values of compressive strength show mixes without fly ash (mix A) and mix with cenospheres (mix CS).

Mixes with cenospheres (mix CS) showed that mixing up to two minutes can be achieved higher value of compressive strength ( 7 days) than mixing by one minute and two times higher value of compressive strength than mixes with fly ash. It can be explained by better forming process of matrix -smaller size of pores are formed and filling components (cement and sand particles) are activated for better grip to nano particles (cenospheres). Comparing to the samples with the fly ash, it can be concluded that the specimens produced using cenospheres have higher values of compressive strength (7 days).

The results of compressive strength of the age of 28 days obtained from all produced FC mixes are summarized in the graph (see Figure 5).

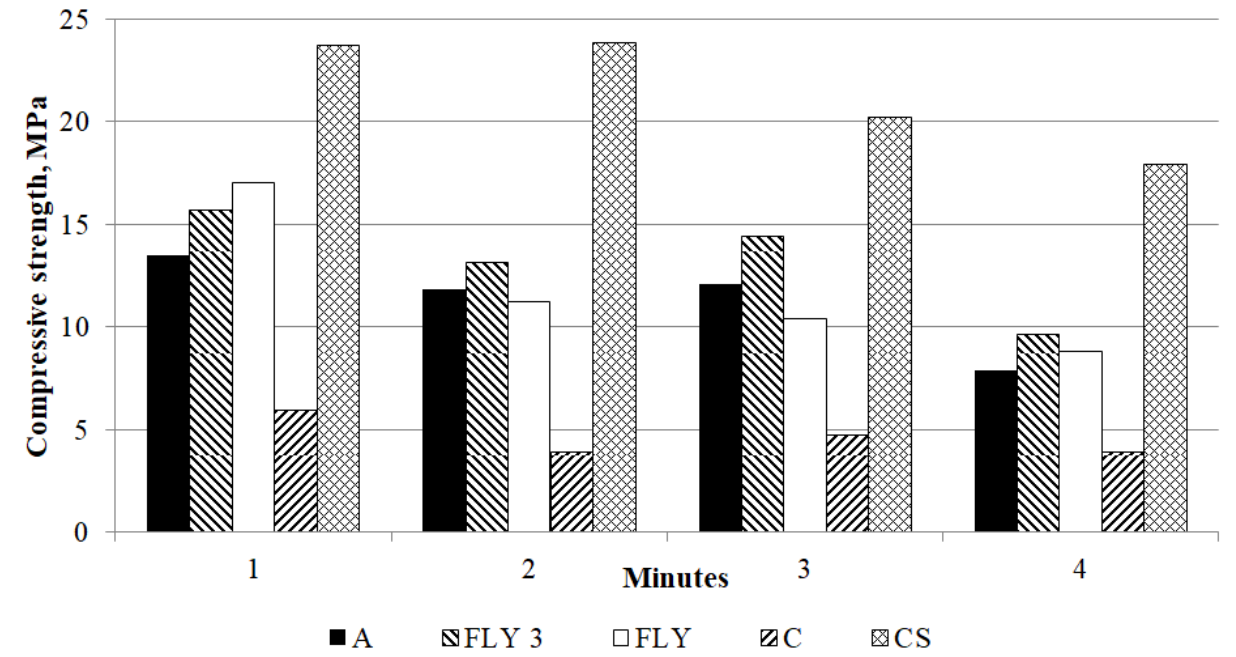

Figure 5. Compressive strength, MPa (28 days) depending on mixing time (minutes)

The higher values of 28 days compressive strength $(23.8 \mathrm{MPa})$ is obtained for mix with cenospheres (mix CS) by activated mixing time from one to two minutes.

It can also be concluded that by use of fly ash value of 28 days compressive strength can be increased. Results of $30 \%$ fly ash show higher value of 28 days compressive strength (see results of mix FLY 3 and mix FLY) and are stabile after one minute mixing time.

The obtained data show that by increasing water/cement ratio decreases the value of compressive strength and are stabile during the mixing time from two to four minutes. The data from this experiment permits to conclude that pozzolanic additives have an effect over time - compressive strength increases up to three times during 28 days.

Capillary water absorption

The results of capillary water absorption are summarized in the graph (see Figure 6).

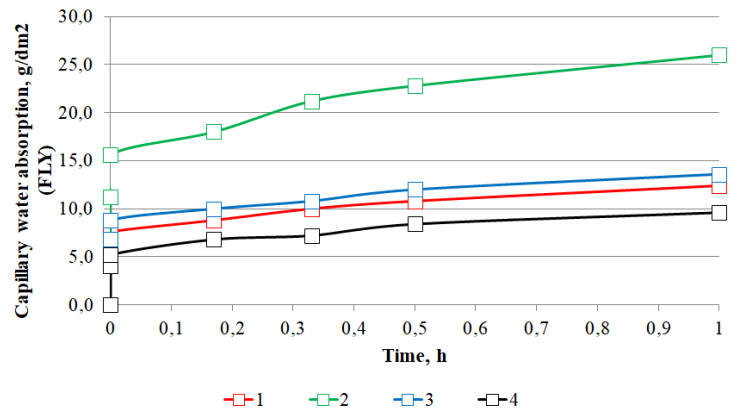

a) Mix FLY (fly ash $11 \%$ by cement mass)

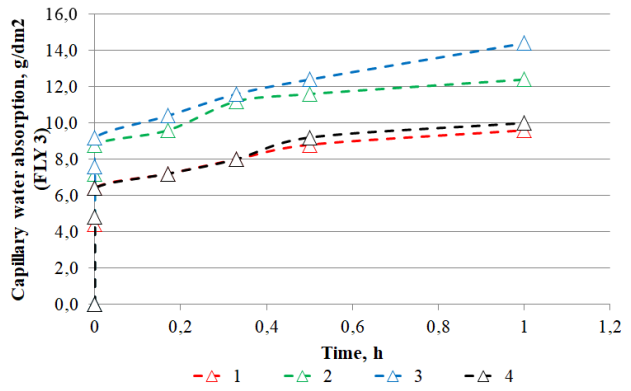

b) Mix FLY3 (fly ash $30 \%$ by cement mass)

Figure 6. Capillary water absorption of mixes with fly ash

The lower values of capillary water absorption present compositions with fly ash. The results show that by using $11 \%$ of fly ash, values of capillary water absorption are in a range of $10-26 \mathrm{~g} / \mathrm{dm}^{2}$. In the case of $11 \%$ of fly content, capillary water absorption was decreased up to $10-14 \mathrm{~g} / \mathrm{dm}^{2}$. 


\section{Microstructure}

The results of microstructure of cross section investigation of FC are shown in Figure 7, Figure 8 and Figure 9.

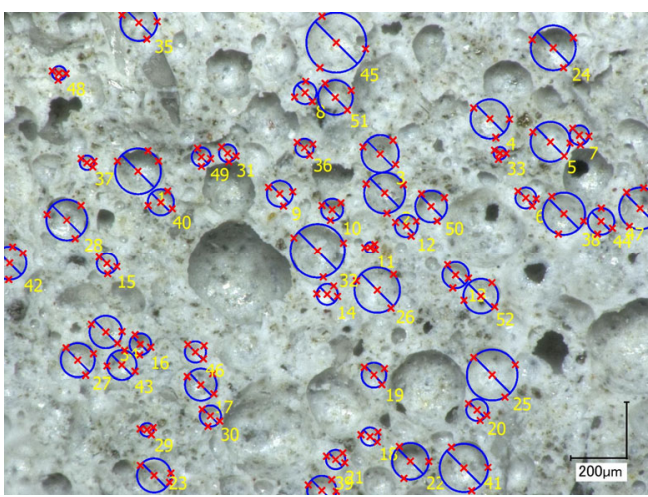

Mix A, $1 \mathrm{~min}$, av.106 $\mu \mathrm{m}$

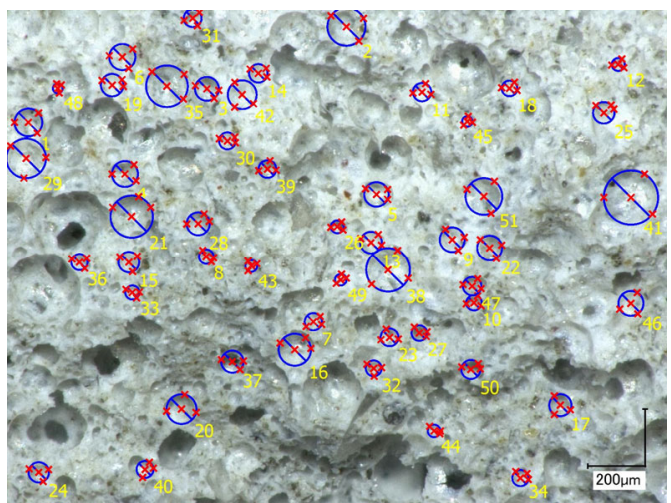

Mix A, 4 min, av. $78 \mu \mathrm{m}$

Figure 7. Cross section view of microstructure

In Figure 7 it can be seen that after four minutes of activated mixing more fine pores are formed (in average $78 \mu \mathrm{m}$ ).

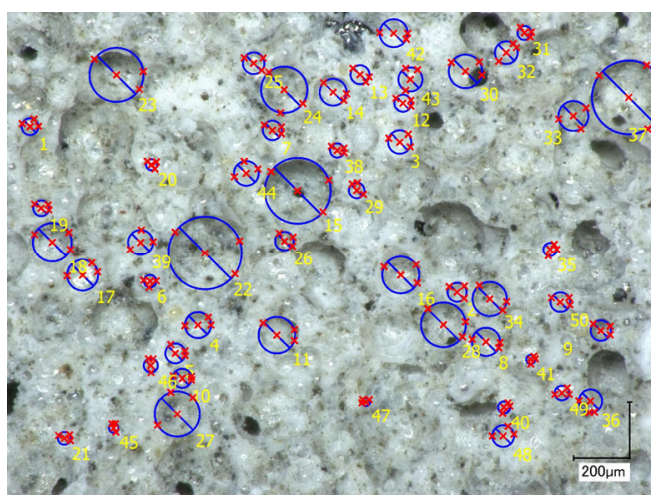

Mix CS, 1 min, av. $92 \mu \mathrm{m}$

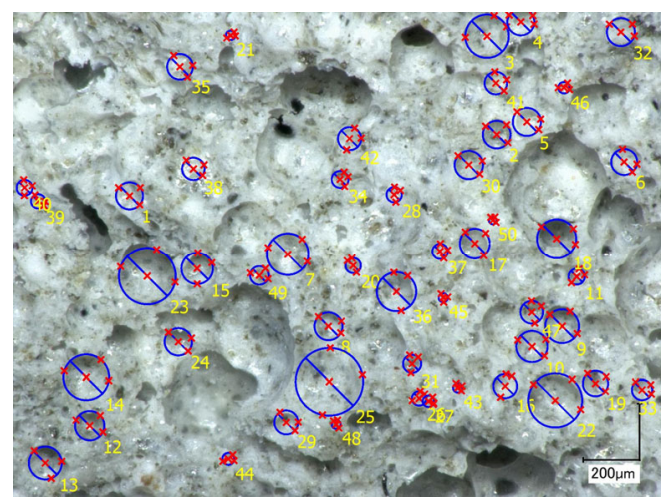

Mix CS, 4 min, av. $90 \mu \mathrm{m}$

Figure 8. Cross section view of microstructure

The results of Figure 8 show that the use of cenospheres doesn't take effect on forming process of microstructure of FC because pore size changes insignificant from $92 \mu \mathrm{m}$ to $90 \mu \mathrm{m}$.

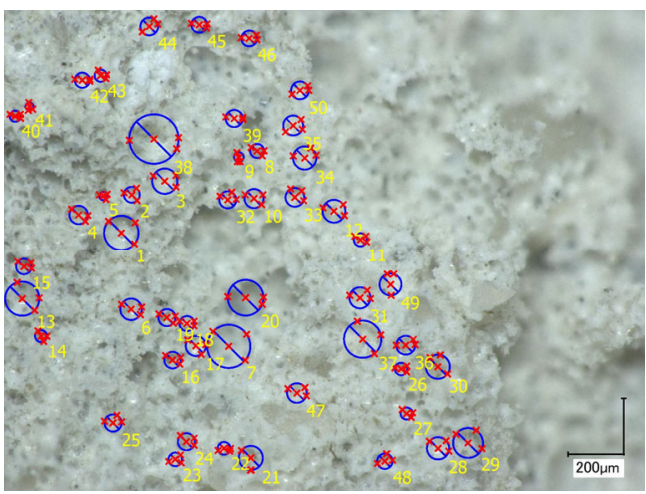

Mix C, 2 min, av. $70 \mu \mathrm{m}$

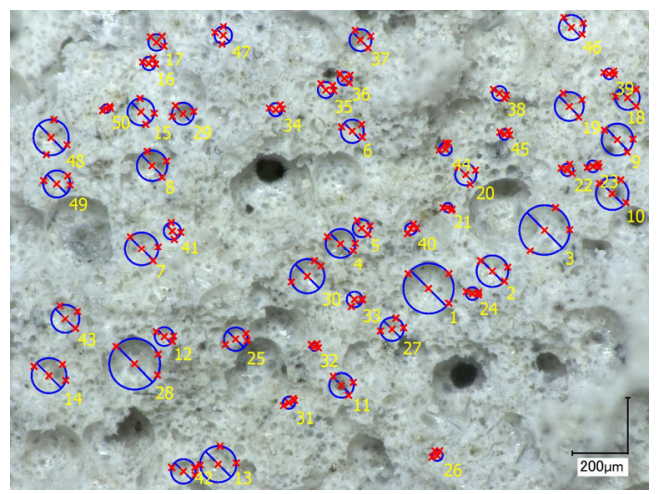

Mix C, 4 min, av. $80 \mu \mathrm{m}$

Figure 9. Cross section view of microstructure

Obtained data from Figure 9 show that by increasing water/cement ratio (up to 0.69) pore size (after one minute of activated mixing) decreases from $106 \mu \mathrm{m}$ to $70 \mu \mathrm{m}$, but after four minute of activated mixing pore sizes become at the same level as in case of 0.49 water/cement ratio. 


\section{Specific compressive strength}

The results of specific compressive strength obtained from all produced FC mixes are summarized in the graph (see Figure 10).

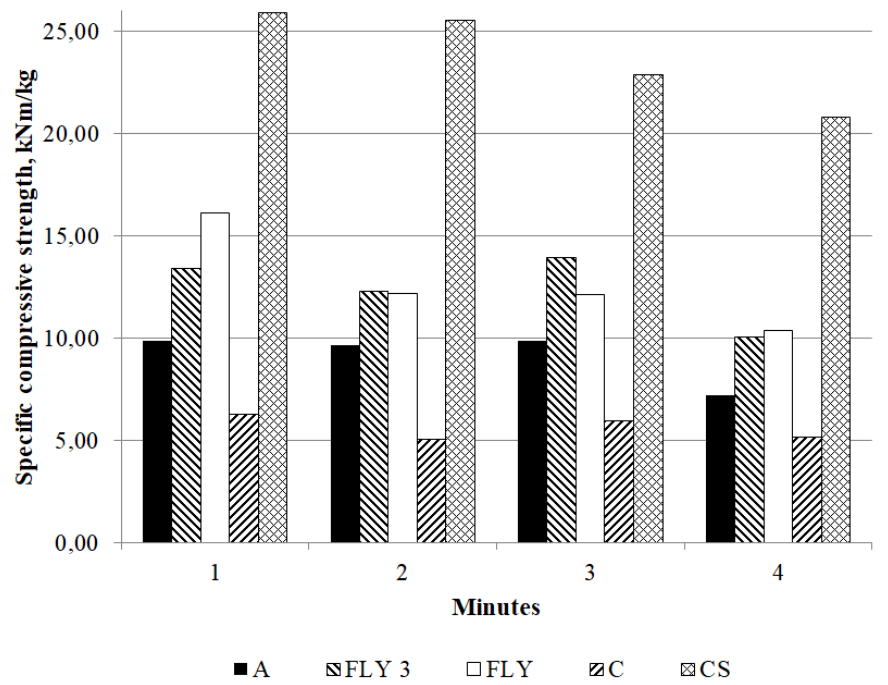

Figure 10. Specific compressive strength, $\mathrm{kNm} / \mathrm{kg}$

The obtained data show that value of the specific compressive strength decreases in a range from $25.87 \mathrm{kNm} / \mathrm{kg}$ to $20.77 \mathrm{kNm} / \mathrm{kg}$ by using cenospheres. Similar results are showed by the mixes with fly ash.

Obtained results show decending tendency from two to four minutes of activated mixing. It can also be concluded that mixes with cenospheres show two times higher values of the specific compressive strength than mixes with fly ash.

\section{Sand/cement ratio}

The results of sand/cement ratio obtained from all produced FC mixes are summarized in the graph (see Figure 11).

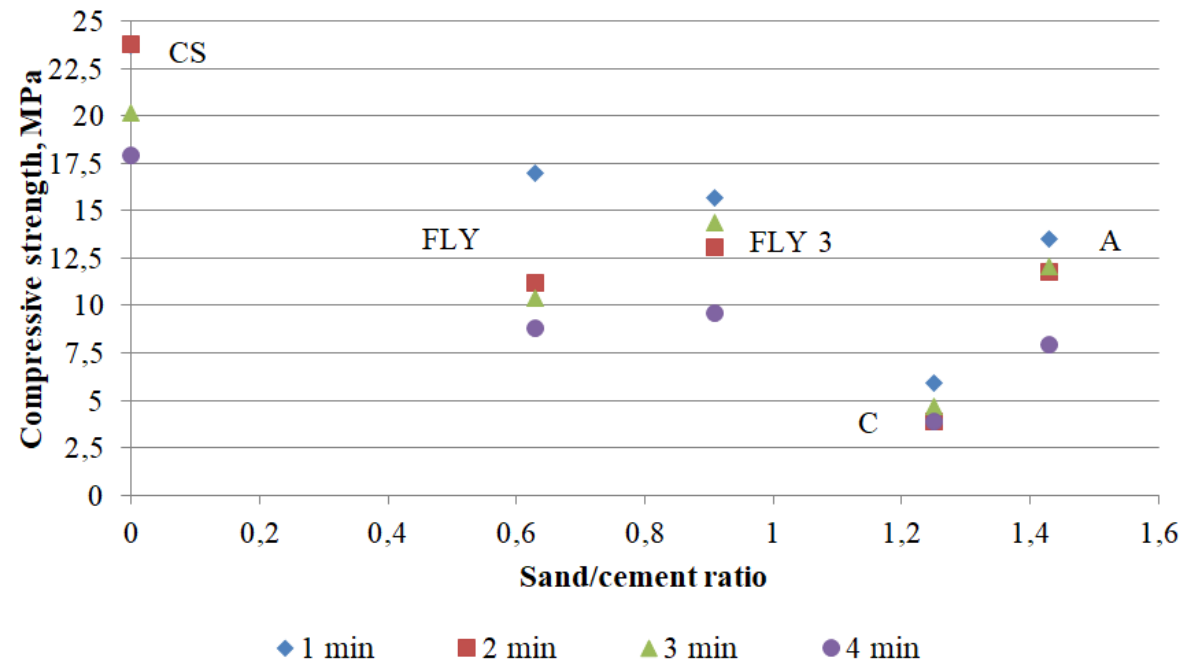

Figure 11. Compressive strength depending on sand/cement ratio, MPa (28 days)

The obtained results show that there is a descending tendency of values of compressive strength by increasing sand/cement ratio. Using pozzolanic additives, values of compressive strength increase and sand/cement ratio decreases. It can be concluded that mix A show lower water/cement ratio by higher values of compressive strength and sand/cement ratio. The opposite result show mix C, where higher water/cement ratio provide lower values of compressive strength and sand/cement ratio. 


\section{Conclusions}

1. First results of innovative mixing technology producing FC by using a planetary ball mill show perspective of application this method and increases the efficiency of this material.

2. The higher value of 28 day compressive strength show mix with cenospheres (mix CS) by activated mixing time from one to two minutes and increase compressive strength up to $25 \%$ (comparing with $4 \mathrm{~min}$ ) at the same density.

3. The lower values of capillary water absorption present mix with fly ash after four minutes of activated mixing, decreasing value up to $63 \%$.

4. There is a descending tendency of values of compressive strength by increasing sand/cement ratio.

5. The optimum activated mixing time for producing FC by a planetary ball mill is between two and three minutes.

6. The use of cenospheres makes possible to achieve high specific compressive strength, but doesn't take effect on forming process of microstructure of FC.

\section{Acknowledgements}

The financial support of European Regional Development Fund project Nr.1.1.1.1/16/A/007 “A New Concept for Sustainable and Nearly Zero-Energy Buildings" is acknowledged.

\section{References}

Cao, W. (n.d.). Synthesis of nanomaterials by high energy ball milling. Retrieved from http://www.understandingnano.com/nanomaterial-synthesis-ball-milling.html

Ding, J., \& Li, Z. (2002). Effects of metakaolin and silica fume on properties of concrete. ACI Materials Journal, 99(4), 393-398. https://doi.org/10.14359/12222

European Union. (2010). Directive 2010/31/EU of the European Parliament and the Council on the energy performance of buildings (pp. 13-35).

Fomenko, E., \& Anshits, N. (2015). Characterization of fly ash cenospheres produced from the combustion of ekibastuz coal. Energy and Fuels, 29, 5390-5403. https://doi.org/10.1021/acs.energyfuels.5b01022

Hwang, C., \& Tran, V. (2015). A study of the properties of foamed lightweight aggregate for self-consolidating concrete. Construction and Building Materials, 87, 78-85. https://doi.org/10.1016/j.conbuildmat.2015.03.108

Just, A., \& Middendorf, A. (2009). Microstructure of high-strength foam concrete. Materials Characterization, 60(7), $741-748$. https://doi.org/10.1016/j.matchar.2008.12.011

Kharitonov, A., Korobkova, M., \& Smirnova, O. (2015). The influence of low-hard dispersed additives on impact strength of concrete. Procedia Engineering, 108, 239-244. https://doi.org/10.1016/j.proeng.2015.06.143

Krämer, C., Kowald, T. L., \& Trettin, R. H. F. (2015). Pozzolanic hardened three-phase-foams. Cement and Concrete Compositions, 62, 44-51. https://doi.org/10.1016/j.cemconcomp.2015.06.002

Latvijas standarts. (2002). Testing hardened concrete - Part 3: Compressive strength of test specimens (LVS EN 12390-3).

Latvijas standarts. (2011). Methods of test for masonry units - Part 11: Determination of water absorption of aggregate concrete, autoclaved aerated concrete, manufactured stone and natural stone masonry units due to capillary action and the initial rate of water absorption of clay masonry units (LVS EN 772-11).

Namsone, E., Sahmenko, G., Namsone, E., \& Korjakins, A. (2017a), Reduction of the capillary water absorption of foamed concrete by using the porous aggregate. IOP Conference Series: Materials Science and Enggineering, 251(1), 012030. https://doi.org/10.1088/1757-899X/251/1/012030

Namsone, E., Sahmenko, G., Namsone, E., \& Korjakins, A. (2017b). Thermal conductivity and frost resistance of foamed concrete with porous aggregate. In Proceedings of the $11^{\text {th }}$ International Scientific and practical Conference Vide. Tehnologija. Resursi - Environment, Technology, Resources (vol. 3, pp. 222-228). Rezekne, Latvia. https://doi.org/10.17770/etr2017vol3.2625

Namsone, E., Sahmenko, G., \& Korjakins, A. (2017c). Durability properties of high performance foamed concrete. Procedia Engineering, 172, 760-767. https://doi.org/10.1016/j.proeng.2017.02.120

Namsone, E., Korjakins, A., Sahmenko, G., \& Sinka, M. (2017). The environmental impacts of foamed concrete production and exploitation. IOP Conference Series: Materials Science and Engineering, 251(1), 012029. https://doi.org/10.1088/1757-899X/251/1/012029

Namsone, E., Sahmenko, G., \& Namsone, E. (2018). Research on properties of high performance foamed concrete. Key Engineering Materials, 788, 13-22. https://doi.org/10.4028/www.scientific.net/KEM.788.13

Retsch GmbH. (2017). General catalogue.

Smirnova, O. (2018). Technology of increase of nanoscale pores volume in protective cement matrix. International Journal of Civil Engineering and Technology, 9(10), 1991-2000. 
Sun, C., Zhu, Y., Guo, J., Zhang, Y., \& Sun, G. (2018). Effects of foaming agent type on the workability, drying shrinkage , frost resistance and pore distribution of foamed concrete. Construction and Building Materials, 186, 833-839. https://doi.org/10.1016/j.conbuildmat.2018.08.019

Tan, X., Chen, W., Hao, Y., \& Wang, X. (2014). Experimental study of ultralight $\left(<300 \mathrm{~kg} / \mathrm{m}^{3}\right)$ foamed concrete. Advances in Materials Science and Engineering, 8, 1-7.

Tanveer, A., Jagdeesh, K., \& Ahmed, F. (2017). Foam concrete. International Journal of Civil Engineering Research, 8(1), 1-14.

United Nations. (2015). Framework convention on climate change 2015 adoption of the Paris agreement (pp. 1-32).

Zhang, J., Jiang, N., Li, H., \& Wu, C. (2018). Study on mix proportion design of cement foam concrete. In IOP Conference Series: Materials Science and Engineering, Conference 4, 439, 1-6. https://doi.org/10.1088/1757-899X/439/4/042053

Zhang, Z., Provis, J. L., Reid, A., \& Wang, H. (2015). Mechanical, thermal insulation, thermal resistance and acoustic absorption properties of geopolymer foam concrete. Cement and Concrete Composites, 62, 97-105.

https://doi.org/10.1016/j.cemconcomp.2015.03.013 